\title{
Management ubiquitous of messages and documents organizational through intelligent agents
}

\author{
Rosa Cano ${ }^{1}$, Juan G. Sánchez ${ }^{2}$ and Cristian Pinzón ${ }^{3}$ \\ ${ }^{1}$ Departamento de Sistemas y Computación, Instituto Tecnológico de Colima \\ Av. Tecnológico s/n, 28976, Villa de Álvarez, Colima, México \\ ${ }^{2}$ Departamento de Informática y Automática, Universidad de Salamanca \\ Plaza de la Merced s/n, 37008, Salamanca, España \\ ${ }^{3}$ Universidad Tecnológica de Panamá \\ Av. Manuel Espinosa Batista, Panamá \\ rdegca@gmail.com, juangabriel@usal.es and cristian.pinzon@utp.ac.pa
}

\begin{abstract}
In the context of artificial intelligence, the multiagent systems are an alternative solution to address complex problems and distributed. PAINALLI is an multi-agent architecture for managing messages and documents organizational anywhere and anytime. To formalize, the management makes use of international standards such as ISO 15489 and MoReq specification. The ubiquity gained in the architecture is due to the use of intelligent agents deployed in fixed and mobile technologies: personal computers, smart phones and personal digital assistants.
\end{abstract}

Keywords: Multi-agent architecture, ubiquitous computing, messages and documents management, MoReq, ISO 15489.

\section{Introduction and motivation}

This paper presents PAINALLI, a multi-agent architecture developed to provide automatic management of internal documents and communication processes in business. The aim of PAINALLI is to formalize and speed up communication among members of an organization, which is commonly based on exchange of messages and documents. Messages are written based on several templates which contain all required and satisfactory elements in order to achieve a better understanding of what is said; documents are attached to the messages after having been cataloged, manually or automatically, depending on their origin. If the document's origin is paper, cataloging is done manually, and if it is electronic, 
it will be cataloged automatically by the system. The cataloging process is supported by the ISO 15489 standard, this norm establishes requirements for the creation and maintenance of documents: authentic, reliable, honest and available, as well as the context or system that must be managed [1]. It helps to ensure quality in an organization, Formby means of a specific guide for managing documents used as a basis for quality systems. An e-mail system is just a communication device, not a document management system. PAINALLI merges an architecture for managing messages (email) and document management.

Sending and receiving documents and messages can be done from both mobile and desktop platform. Such feature is one of the PAINALLI's advantages over other related products, using personal computers, PDAs (Personal Digital Assistant) or smart phones. The use of a formal process to design the architecture, the use of templates as a base for message encoding, the feedback that ISO 15489 standard and MoReq, this specification describes a model of requirements for managing electronic documents and archives and affects especially in functional requirements for managing electronic documents and archives through a system of electronic document management file (SGDEA) [2] both provided for documents management and the support of desktop and mobile technologies make PAINALLI a robust system, reliable in its functional performance and employment.

The communication process is a key element in current organizations. In order to understand it we will take the elements quoted in the definition introduced by [3]: message, channel, sender, receiver, transmission, encoding and decoding, meaning, feedback and communication effects. The last five ones are the most relevant elements for this project, because they are the focus of our investigation work's hypothesis. A message encoding must be formalized so the receiver can decode it and interpret the exact meaning of what the sender is expressing. Any message's aim, being accompanied by a document or not, is at generating one or more actions as a result or effect from the communication. For this purpose, the sender must receive some feedback from the receiver; we will call this messages exchange as "conversation". At the present time, organizations demand tools not only for making the communication process easier. It is essential to add them some obligatory and sufficient features to provide them with intelligence, being able to support every element of the process.

A very useful and suitable technology to develop multi-platform systems consist on agents and multi-agent systems (MAS), which are composed by several agents interacting with each other, making able together to reach the desired functionality [4]. An agent is an entity that must have certain characteristics, like: autonomy, situation, reactivity, proactivity, social ability, learning capacity, mobility or organization [5]. BDI agents have got the mental states of Beliefs, Desires and Intentions [6]. It has likely been the most spread and studied model among agents reasoning models, and because of that it is the most advisable one for agent-based applications development [7]. A critical drawback for development an agent-based architecture is that, at the present time, we lack of 
clear standards or completely developed methodologies that set up the steps to realize correct analysis and design [8]. Based on the experience of the BISITE (Biomedicine, Intelligent Information Systems and Educational Technology) research group from the University of Salamanca, a suitable combination for multi-agent architectures development is to use the Gaia methodology and the AUML modeling language.

One of the advantages provided by the multi-agent systems is the ability of agents to run on mobile devices. Nowadays there is a growing need to find more effective ways to offer services in mobile devices [9] such as digital personal assistants and mobile phones, using communication technologies like GPRS (General Packet Radio Service), UMTS (Universal Mobile Telecommunications System), Bluetooth, etc. The versatility of mobile devices offers an opportunity that has to be taken into account in order to make the personnel an organization come closer. By means of those, a person will be able to, whenever or wherever he is access organizational information as if he was in his own office. Software systems that integrate the use of mobile technologies to their solutions, as PAINALLI system does, are more robust because provide users the possibility of accessing the system from any place and at any moment they may require.

\section{Related work on organizational communication}

Nowadays, society demands more and better products and services, and as a result organizations need to count on business strategies in order to provide a way for their employees communicate and fulfill their clients and workmate's expectations more efficiently. The internal communication process in an organization is a key factor for its members being able to interact, because by means of such interactions, it is possible to achieve the organization's strategy goals. The vast amount of information generated in an organization, product or its domestic efforts of the interaction it has with other outside entities, usually is generated and stored on paper, the main drawbacks associated with this are the unknown the amount of information generated and the lack of standards for: development, classification, management and retrieval of documents. Through computer systems it is possible to solve these problems, which allows formalizing and systematizing processes associated with the generation, use, storage and retrieval of documents.

It is necessary that organizations count on a mailing system that guarantees an appropriate use of itself, the pure fact that electronic mail arrives sooner doesn't mean that the effort in mechanical details is going to last shorter [10]. This reasserts the proposal presented with PAINALLI, electronic mail per se is not the solution to communication problems; formalization is required in order to make the communication process efficient. 
The purpose of establishing a CDMS (Corporate Documents Management System) is to provide a documents management model and a software tool that guarantees access to information and its availability in order to improve productivity, mind capital and knowledge [11]. Formalizing the process of creating a CDMS requires using some standard or methodology as a reference. PAINALLI was developed using ISO standard 15489:2001 and MoReq [2].

In the IV study about internal communication in Spain [12], elaborated by "Infopress", the "Instituto de Empresa" and the "Capital Humano" magazine, presented the following results: $68.7 \%$ of organizations are equipped with an internal communication plan. Descendant information is more effective than ascendant. The main capabilities that directives must improve are empathy with employees (81.1\%) and the ability to expose appalling (79.3\%). Directives say that company results would improve in $90.7 \%$ if there was better commitment with communication, and also that it would let decisions being taken faster in $85.6 \%$, those decisions affecting directly to the results account. In view of such facts, we can say that a software system such as PAINALLI, which supports the internal communication system, would present a significant impact for the organization and its economic resources.

The $9^{\text {th }}$ AIMC (Communication Media Investigation Association) survey on Internet users shows that [13]: $75.1 \%$ of users polled use a program to block popups and $76.1 \%$ to eliminate or filter unwanted email (spam). $51.8 \%$ of them have a personal email account at work or college. The most employed email software is the Microsoft Outlook (40.6\%), followed by webmail (25.1\%). Subsequently to desktop computers and laptops, 94.7\% and 51.5\% respectively, mobile phones with $20.5 \%$ and PDAs with $9.3 \%$ are the most employed equipments to access the Internet. PAINALLI is a platform that avoids non wanted emails and pop-ups. It is specifically designed to manage messages among members of an organization. Besides, it is built with the required and adequate structure to formalize communication, thus giving users the possibility of accessing their messages and documents through two technologies: wired or wireless.

In economic terms, the use of electronic mail and documents management reduce costs significantly. Apart from being cheaper, they represent a way of saving economic resources in organizations. Traditional archiving costs can be reduced in three aspects: salary, administrative and chance loss [14]. On the other hand, Boronat classifies costs in: localization and recovering, distribution and storing [15]. A critical drawback organizations might face is the incidence of unwanted email or spam (non-requested messages), besides, they can bring viruses. In July, 2007, Panda Software presented a report which said that $88 \%$ of emails in companies were spam [16]. A study carried out by Dimension Data over 524 companies along the USA and other 12 countries of Europe, Middle-East, Africa and Asia says that $99.6 \%$ of the employees and executives use email to communicate at work [17], in a study alike stresses the fact that the communication type must be formalized so the communication process becomes 
efficient and secure. Taking into account the needs of modern organizations, we have provided some functionalities.

\section{Overview}

PAINALLI is a multi-agent architecture structured by interactions of intelligent agents that manage sending and receiving messages and documents. The platform's development has been carried out using Java programming language and JADE framework (Java Agents Development Environment). Combining these tools allowed us to build an easy-to-use multi-platform system based on a distributed technology of well-known efficiency. The user accesses the system through an intuitive interface helped by ex profeso designed templates. Users are able to write messages and attach electronic documents to them. This kind of access is available using personal computers or mobile devices such as smart phones or PDAs. The user may send a message with PAINALLI using one of the templates available, which let him Inform, Ask, Request or Arrange a Meeting with the receiver, who in turn may answer the message and attach a document if he needs to. The owner of the conversation (sequence of messages about one specific subject) is the one who sends the first message and, as a consequence, he is the only one who may delete the conversation from the server and consider it concluded. PAINALLI provides advanced automatic conversation management, as well as knowledge extraction techniques which allow obtaining a better understanding of communication processes inside the organization and a support system for decision making.

Management of registered, created or received information, which is stored as pure or test information, by an organization in the exercise of its activities [18] is the scope of application of documents management realized in PAINALLI platform. This is achieved by means of the agents in charge of visualizing, cataloging, storing and recovering the electronic documents [19] sent as attached files. If the document is printed, it may be converted to an electronic format to be considered as that. MoReq specification and ISO standard 15489 [2] are the tools used to make PAINALLI's documents management more robust.

Users of PAINALLI have a personal agenda which contains every commitment acquired from conversations with other/s member/s of the organization. There is one special agenda called "Institutional Agenda" where users can publish information of institutional interest. One way of formalizing commitments is by means of an acknowledgement of receipt, got by the sender, when the message has been opened by the receiver.

Commonly, organizational structure is based on functional areas or departments and in addition there may be committees or groups integrated by people from different departments or areas. It is possible to send messages and documents to a specific person, a group of people or to everyone in the 
organization. People in charge of an area or department have the possibility of knowing the productivity level of each one of their subordinates. All information is stored in a database. Critical information is kept encrypted.

\subsection{Model proposed}

The formalism and system-based approach achieved during analysis, design, implementation, testing and deployment of a software product is obtained by employing techniques, tools, methodologies and languages. In the case of PAINALLI we take the Gaia methodology as reference, which mainly aims at providing a system analysis method and at designing its structure from a series of initial requirements, obtaining several models that allow us to define and analyze the basic structure of the system [20]. The Gaia methodology incorporates novel software engineering mechanisms, based on the artificial intelligence perspective. Gaia analyzes the problems focusing on social and organizational concepts, which allows obtaining models adapted to the user behaviors. The models obtained with Gaia are refined and adapted using AUML, getting a series of diagrams that provide a model of the system close to implementation [21].

The aim is to generate a multi-agent architecture which supports sending and receiving messages, by means of ex profeso elaborated templates, and sending documents attached to messages. Figure 1 shows the architecture which models the agents who, through their performance and interaction, allow PAINALLI users to use the tools offered by the platform.

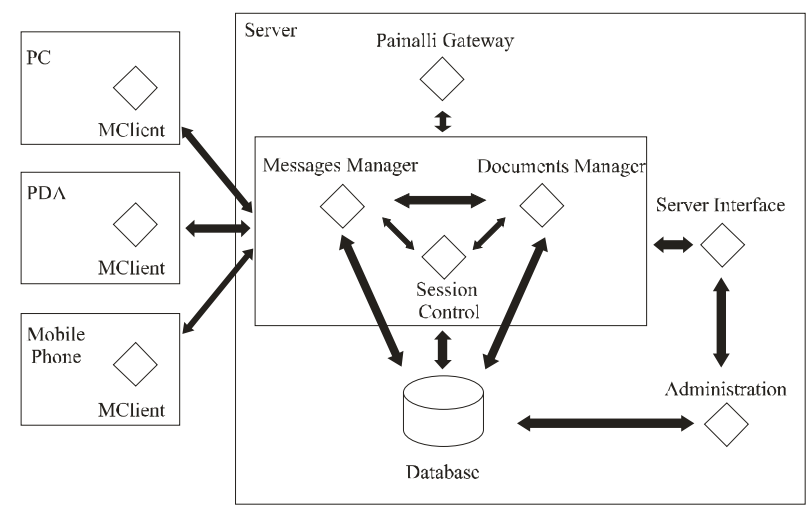

Fig. 1. System Architecture

The Gaia agent model was developed based on roles observed in these kinds of problems, and the communicative acts among such roles. The agent types that make up the architecture are: PCClient, MClient, MessagesManager, DocumentsManager, AgileGateway, SessionControl, ServerInterface, and Administration. After obtaining the agents model and following the GAIA 
methodology, the acquaintance model was created as shown in figure 2. In this model it is possible to observe the communication flows among agents.

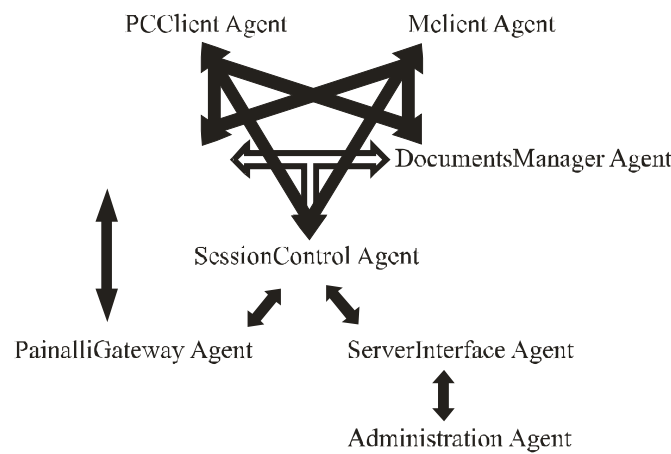

Fig. 2. Acquaintance Model

In order to analyze the system's functionality by means of agents collaboration, an interaction model was developed. Figure 3 shows an example of interaction diagram for opening a session, this interaction consists of two protocols. First, the Client role sends a login request to SessionControl, indicating its login and password. SessionControl checks the information in the database and, if the user exists and the password is correct, grants the Client access to the system. After that, the protocol "Get New Messages" is executed: the Client asks MessagesManager for its new messages, and the latter recovers them from the database and sends them to the Client.

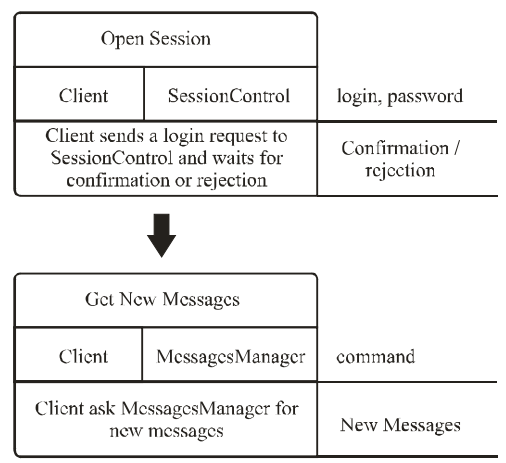

Fig. 3. Opening a session interaction diagram

\subsection{AUML diagram}

Once the Gaia methodology finishes, it is necessary to detail the results obtained. The "Request" template contains the following elements: receiver(s), subject, 
message, format, date and time, and an optional attached file. The message is sent by agent $\mathrm{A}$ to the MessagesManager agent, which asks the SessionControl agent if agent $A$ is logged in as a valid user. If so, it forwards the message to agent $B$, who is one of the receivers of the message. When agent $B$ receives the message, an entry is created into the user's agenda that describes the request. When B has the information requested, he can hand it in to A, which includes another valid-user checked by the MessagesManager and SessionControl agents, figure 4 shows the corresponding diagram.

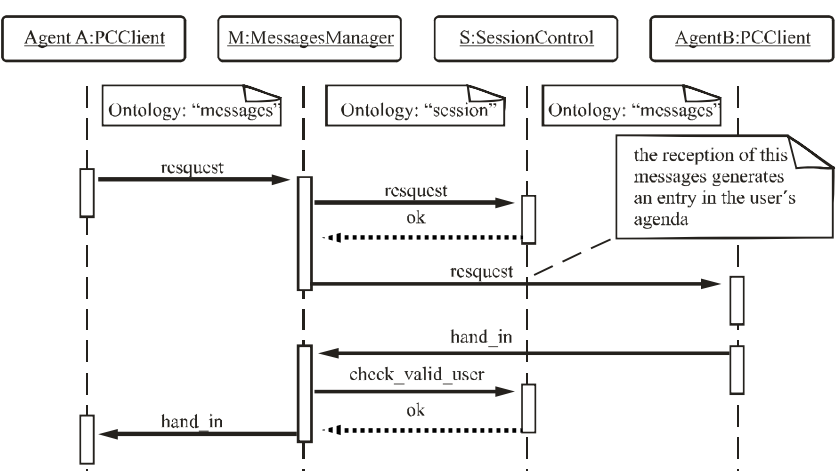

Fig. 4. "Request" template diagram

\section{Results and Conclusions}

Taking into account the consulted bibliography we can say that the organizations' communication process needs formalization and that a software system is a tool able to support and make it better through techniques and standards belonging to messages and documents management.

A message and document management system like PAINALLI can be developed as an intelligent agent's platform. MAS are a robust technology that supplies all required and sufficient versatility to carry out the messages and documents interchange by means of agents' interacting within wired or wireless networks.

Through the templates used in PAINALLI ("Arrange a meeting”, "Ask", "Inform" and "Request"), users can communicate easier with their mates. In each message it is possible to attach a document, which is cataloged by the Documents Management agent.

In picture 5 we can see the dialog box for the "Request" template. On the left side of the dialog there is a "receivers panel", where we can pick the employees or groups which we want to receive the message. The upper side of this panel shows the company structured in groups and employees who belong to them, and the lower side shows all employees alphabetically sorted. The rest of the dialog lets us 
to enter the request details, such as subject, message, format in which we want to receive the information, limit date and time, and finally, it allows us to attach a document to the message.

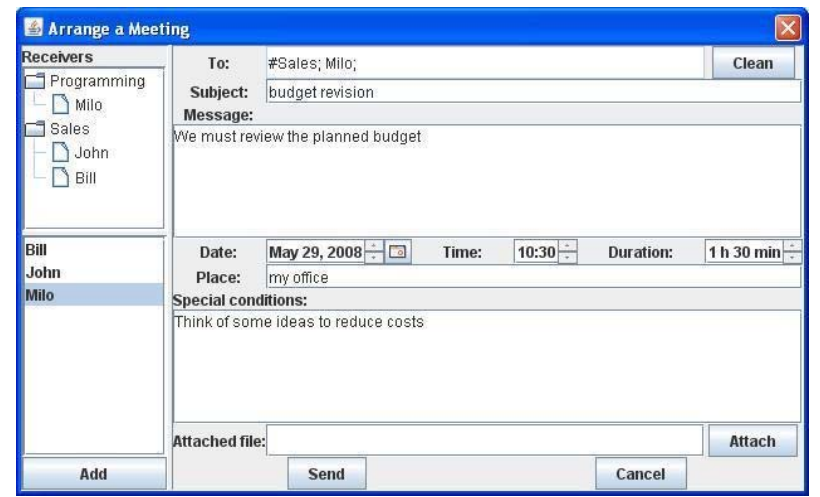

Fig. 5. Dialog box for the "Request" template

We achieved competitive results on the experiments done with the prototype, where it was considered variables like: storage capacity, security, performance and utilization tests. With regard to document management, PAINALLI can carry out actions such as cataloging, storing and recovering documents.

PAINALLI has been evaluated by expert from Tulecom Group, Flagsolution and Matchmind. They have analyzed the proposal model and correspondence with other applications. Results are shown in table 1.

Table 1. Results table

\begin{tabular}{lccccc}
\hline & Gmail & Yahoo & Lycos & Hotmail & PAINALLI \\
\hline Storage capacity & Excellent & Excellent & Very good & Acceptable & Excellent \\
Security & Good & Good & Acceptable & Good & Very good \\
Performance & Very good & Very good & Good & Good & Excellent \\
Utilization tests & Excellent & Very good & Good & Acceptable & Excellent \\
\multicolumn{1}{|c|}{ Total } & Excellent & Excellent & Good & Acceptable & Excellent \\
\hline
\end{tabular}

In future works the prototype will be tested with different kinds of organizations (public and private) to contrast the results obtained with PAINALLI against other commercial and free-of-charge products of the market to know and demonstrate the efficiency of the platform.

Acknowledgements. This work has been supported by the MCYT project TIC2003-07369-C02-02. We also thank Tulecom Group, Flagsolutions and Matchmind for their support and collaboration. 


\section{References}

1. Organización Internacional de Normalización (2006) ISO 15489-1:2001. Información y Documentación. Gestión de Documentos. Parte 1: Generalidades. AENOR, España

2. Gómez Domínguez, D., Ruiz Rodríguez, A., Peis Redondo, E. (2003) La gestión de documentos electrónicos: requerimientos funcionales. El Profesional de la Información. Vol. 12, pp. 88-98

3. Krone, K., Janblin, F., Putman, L. (1987) Communication Theory and Organizational Communication: Multiple Perspectives. In: Handbook of organizational communication. Sage Publications

4. Bussman, S., Müller, H. J. (1993) A communication architecture for cooperating agents. Computers and Artificial Intelligence. Vol. 12, pp. 37-53

5. Wooldridge, M.J., Jennings, N. R. (1994) Agent theories, architectures and languages: a survey. In: ECAI94 Workshop on Agent Theories Architectures and Languages

6. Haddadi, A., Sundermeyer, K. (1996) Belief-desire-intention agent architectures, foundations of distributed artificial intelligence. In: Foundations of distributed artificial intelligence, pp. 169-185. Wiley-Interscience Publication

7. Rao, A.S., Georgeff, M. P. (1995) BDI agents: from theory to practice. In: Proceedings of the First International Conference on Multi-Agents Systems

8. Bajo, J., de Luis, A., Tapia, D. I., Corchado, J. M. (2006) Sistemas multiagente inalámbricos basados en agentes CBR-BDI: de la teoría a la práctica. In: $5^{\circ}$ Workshop internacional sobre aplicaciones prácticas de agentes y sistemas multiagente

9. Rigole, P., Holvoet, T., Berbers, Y. (2002) Using Jini to integrate home automation in a distributed software-system. In: DCW '02: Revised Papers from the 4th International Workshop on Distributed Communities on the Web

10. Flynn, N., Flynn, T. (2001) Correo electrónico: cómo escribir mensajes eficaces. Editorial Gedisa, S. A.

11. De Inclán, M. (2006) Actuaciones para la implantación de un sistema de gestión documental corporativa: experiencia del Banco de España. In: VIII Jornada de Gestión de la Información

12. Cabanas, C., Vilanova, N., Carazo, J. A. (2005) IV Estudio sobre la comunicación interna en España. Technical report, Instituto de Empresa, Observatorio de Comunicación Interna e Identidad Corporativa, Grupo Inforpress y Capital Humano

13. AIMC (2007) Navegantes en la red: 9a encuesta AIMC a usuarios de Internet. SERSA

14. Martínez Sereno, V. (1998) Integración de sistemas de gestión electrónica documental en la empresa: evaluación y metodología de implantación. In: VI Jornadas Españolas de Documentación

15. Boronat, F., Cicuéndez, R., Lloret, J. (2005) Sistema de gestión electrónica de documentos del servicio de reprografía de la EPSG. In: XX Simposium nacional URSI

16. Panda Security, http://www.canal-ar.com.ar

17. Clarín, http://www.clarin.com

18. Bustelo, C. (2007) Gestión de documentos: enfoque en las organizaciones. Anuario ThinEPI, pp. 141-145

19. García Pérez, A. (2001) La gestión de documentos electrónicos como respuesta a las nuevas condiciones del entorno de información. ACIMED. Vol. 9, pp. 190-200

20. Wooldridge, M. J., Jennings, N. R., Kinny, D. (2000) The Gaia methodology for agentoriented analysis and design. Autonomous Agents and Multi-Agent Systems. Vol. 3, pp. 285-312

21. Bauer, B., Huget, M. P. (2003) FIPA modeling: agent class diagrams. Working Draft, foundation for Intelligent Physical Agents 